\title{
FREQUENCY ANALYSIS OF PHYSIOLOGICAL AND NEUROTIC TREMORS
}

\author{
BY \\ J. W. T. REDFEARN
}

From the Army Operational Research Group, West Byfleet, Surrey

It seems reasonable to assert that the diagnostic distinctions between the common organic causes of tremor emerged clearly during the sixties of the last century, and that this was partly due to the work of Charcot and his pupils. At this time also the Marey tambour (Marey, 1868) came into widespread use. These two circumstances seem to have been responsible for the first attempts to study graphical records of tremor by Charcot's pupils, and it was in turn upon these experimental results that Charcot based his later teaching (Charcot, 1888, 1889) on tremors. He divided the non-intentional tremors into three main groups: (1) Slow, 4-5 per

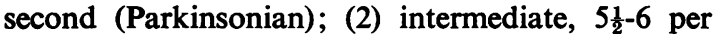
second (hysterical); (3) rapid or vibratory, 8-9 per second (Basedow's disease, alcoholism, general paralysis of the insane).

As far as the tremors of neurosis are concerned, Charcot's later pupils (e.g., Dutil, 1891) were able to show that this scheme was an oversimplification and that hysterical tremors, for example, were often vibratory in type. Since then there has been little advance in our knowledge of the neurotic tremors. Most clinicians have simply divided neurotic tremors into the categories of coarse and fine, corresponding with the intermediate and the vibratory groups respectively. The coarse tremors are commonly associated with hysteria and are often, on the basis of wartime experience, held to carry a better prognosis than the fine tremors, which are commonly associated with anxiety and other neuroses (Mott, 1919).

Meanwhile Schäfer (1886) had demonstrated a 10-per-second rhythm in the normal human voluntary myogram, and a majority of subsequent authors have found this to be the predominant frequency of physiological tremor.

Theories sometimes held to account for this family of physiological and neurotic tremors may be summarized as follows: (a) That the rhythm is determined by the mechanical properties of the muscle or of the muscle twitch; (b) that it is due to the delayed self-correction inherent in the stretch reflex; (c) that there is some intrinsic rhythmical propensity at the spinal level; and $(d)$ that the rhythm is due to driving by higher centres, e.g., the motor cortex. It must be observed that the relationship between "physiological", emotional, thermal, and neurotic trembling has never been precisely defined. It is therefore not usually possible to be clear as to exactly which type or types of tremor these theories are held to explain.

This paper describes the frequency analysis of normal and neurotic tremors, the results of which suggest a common physiological basis. The definition of a neurotic tremor used in this paper is a tremor occurring in a person suffering from neurosis. It will be seen that from the point of view of the harmonic components of neurotic tremors, they are largely an exaggerated form of physiological tremor. The above definition is therefore a logical necessity.

\section{Methods}

It was decided to record finger displacement rather than finger velocity, acceleration, or the forces exerted by the finger. It is the displacement and not the velocity or acceleration of the finger which is seen by the clinician as tremor. And secondly, it is possible to obtain records of velocity or acceleration from the displacement record by the simple mathematical or electronic means to be described here.

An inertialess system of recording was felt to be necessary, as the effect of the inertia of the trembling part (see Halliday and Redfearn, 1956) was not clear at the time of the experiments to be reported here, and indeed a study of this factor was one of the first items on the experimental programme (Redfearn, 1957, Appendix F).

The recording method used, although later modified by Cooper and Halliday, was essentially the same as that described by Cooper, Halliday, and Redfearn (1957) (for details of the earlier version see Redfearn, 1956). The index finger or other trembling part interrupted a parallel beam of light and cast its shadow over the lower half of a slit placed in front of a photocell. The output from the photocell, which was linearly related to the angular displacement of the finger, was amplified by 
means of a capacity coupled push-pull amplifier with a time constant such that there was less than $5 \%$ loss at $1.5 \mathrm{c}$./sec. The output from the amplifier was used in a Hughes four-pen recorder. The other channels of recording comprised a signal-marker channel, a record of the velocity or acceleration of the finger as obtained by one or two stages of electronic differentiation, and (usually) the electromyogram of the common extensor of the fingers obtained from surface electrodes. The instrument was calibrated by rotating an elliptical disc in front of the slit. The relationship between shadow displacement and pen displacement was linear over the range used. The subject was seated comfortably with his right forearm supported as in an armchair. The right forearm, wrist, and the fingers not being used for recording were immobilized as far as practicable by splints and bandages. Only movement at the metacarpophalangeal joint was allowed, the finger being immobilized distal to this joint by means of cellulose tape. The subject was asked to extend his finger comfortably, not rigidly, so that its shadow fell across the photocell slit. No precise aiming was required. Only severely depressed patients were found to allow their fingers to sag sufficiently for the shadow to fall away from the slit. No such patients were among the groups to be described.

The photocell housing, the rest for the forearm and hand, and the lamp housing were all supported in a robust steel and concrete structure so as to avoid any artefacts due to vibration under normal recording conditions. Artefacts produced deliberately by knocks and bangs applied to various parts all had a high frequency many times those considered in this paper.

The stretch reflexes in the muscles extending the finger were recorded by subjecting the finger to a very sudden change in tension and recording the resulting changes in acceleration. The method is described by Cooper $e t$ al. (1957).

The tremor records were subjected to analysis of their harmonic composition. The method of analysis used was the Army Operational Research Group wave analyser, which is a modification of the Admiralty Research Laboratory frequency analyser (Barber, Ursell, Darbyshire, and Tucker, 1946). The original record (a) (Fig. 1) was enlarged and converted to a black-and-white silhouette $(b)$ on a strip of paper. This was placed on the circumference of a drum which was made to rotate with varying speed. The trace was analysed into its harmonic components by a combination of photocell and selective amplifier and each harmonic component written out as a pen deflection, thus yielding a line spectrum $(c)$. Each analysis corresponded with a duration of record of about four and a half seconds. In addition to the frequency analysis of each record the total tremor was measured in units of mean angular finger velocity by planimeter.

\section{Procedure}

Twenty-nine normal and 32 neurotic young men were studied. Tremor and stretch reflex records were taken, and each man was subjected to a psychiatric interview in which certain items in the anamnesis were recorded and a clinical diagnosis made. The normal men were con- valescent from various minor physical disabilities or maladies, and the neurotic group represented the population of two psychoneurotic wards of a military hospital. The records were taken by technical assistants on the day following the clinical interview. These technical assistants were of the same age and seniority as the subjects and the entire recording procedure was made as matter-offact and reassuring as possible. Several tremor records were taken from each subject, at intervals of two or three minutes. There was no tendency for the tremor to change during the recording session and so average values for all records could be taken. It had been expected that tremor would subside as the subject became more accustomed to the procedure but no such trend occurred over the period of 20 minutes or half an hour during which records were being taken.

The qualitative clinical diagnoses being of no use for the statistical purposes intended, each subject was given a rating on a scale of hysteria, a scale of anxiety, a scale of depression, and one of tension. As only six patients showed any tension at all this last scale could not be used statistically, although the mean tremor amplitude for the patients with tension was a good deal higher than for those without. A brief description follows of the criteria used for rating.

In view of the virtual absence of text-book features of hysteria in most members of the neurotic group, the rating of hysteria was based on the degree of discrepancy between the emotional display of which the patient was aware, and his real feelings as judged from those manifestations of emotion of which he was not aware, and from his general conduct. The characteristic being rated under this heading is well described by Bleuler (1924) in the English translation of whose text-book one reads:-

"In the purely psychic sphere one might mention the following permanent symptoms, which though belonging essentially to the hysterical disposition are also re-inforced by manifest hysteria: lability of the affects, moodiness, momentary reactions in all relations, with exaggerated affective outburst in various directions. The latter display mostly something of the theatrical; one has the feeling that the real affective force displayed does not quite correspond to the amount of crying and tears. ... Under certain constellations hysterics may temporarily or lastingly appear indifferent, poor in feelings, just like in an affective torpor."

Thus the hysterical individual may be putting up too much of an emotional display, or not enough, to be consistent with what the psychiatrist judges to be his real feelings. This was the criterion used here. Of the criteria used it was far the most reliable in practice. The rating was carried out on a four-point scale, according to whether these characteristics were absent, present, marked, or florid.

The severity of anxiety was rated in a similar manner, according to whether it was absent, present, or marked. No sufficiently severely anxious patients were in the group to be placed in the fourth category which had been reserved. The amount of anxiety was assessed according to the patient's statements about his feelings and present 


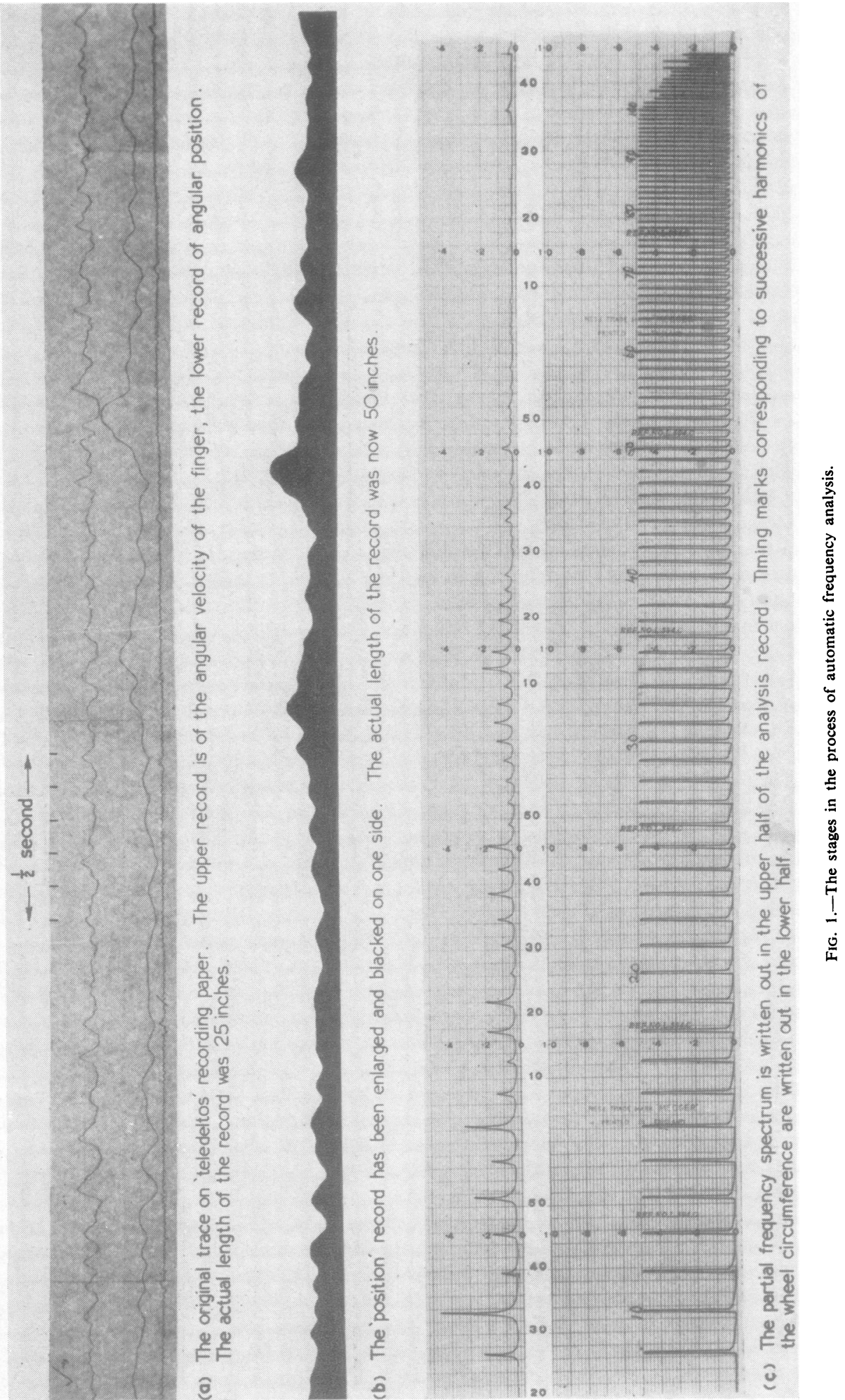


TABLE I

MAIN CLINICAL FEATURES AND MEAN FINGER VELOCITIES OF NEUROTIC CASES

\begin{tabular}{|c|c|c|c|c|c|c|}
\hline \multirow{2}{*}{$\begin{array}{l}\text { Case } \\
\text { No. }\end{array}$} & \multirow{2}{*}{ Main Clinical Features } & \multirow{2}{*}{$\begin{array}{l}\text { Clinical } \\
\text { Diagnosis }\end{array}$} & \multicolumn{3}{|c|}{ Clinical Ratings for } & \multirow{2}{*}{$\begin{array}{l}\text { Mean Angular } \\
\text { Finger Velocity } \\
\left(\text { rad./sec. } \times 10^{-3}\right)\end{array}$} \\
\hline & & & Hysteria & Anxiety & Depression & \\
\hline N1 & $\begin{array}{l}\text { Complains of tremor due to bad nerves, of all parts of body. } \\
\text { Denies any affect associated therewith. Looks prematurely } \\
\text { old and expressionless. }\end{array}$ & $\begin{array}{l}\text { Hysterical } \\
\text { tremor }\end{array}$ & 2 & 1 & 1 & $68 \cdot 3$ \\
\hline N2 & $\begin{array}{l}\text { Complains of feelings of unbearable tension and murderously } \\
\text { aggressive feelings towards officers. Thinks he may have a } \\
\text { split mind. Restless, jumpy, smokes } 40-50 \text { cigarettes a day. }\end{array}$ & $\begin{array}{l}\text { Tension } \\
\text { state }\end{array}$ & 1 & 2 & 0 & $44 \cdot 4$ \\
\hline N3 & $\begin{array}{l}\text { Complains of stomach pains, dizzy spells, weeping spells, } \\
\text { worries about things at home, hates Army. Childish } \\
\text { manner. }\end{array}$ & $\begin{array}{l}\text { Anxiety } \\
\text { state }\end{array}$ & 1 & 2 & 1 & $25 \cdot 7$ \\
\hline N4 & $\begin{array}{l}\text { Complains of anxiety state of } 9 \text { years' duration. Has dizzy } \\
\text { spells, feels weak over whole of left side, worries about } \\
\text { masturbation. Palpitations, bad dreams. }\end{array}$ & $\begin{array}{l}\text { Mild anxiety } \\
\text { state }\end{array}$ & 1 & 1 & 1 & $33 \cdot 3$ \\
\hline N5 & $\begin{array}{l}\text { Wandered off in a fugue for a day. When he "came to" } \\
\text { people's faces looked like gargoyles. Complains of a grey } \\
\text { outlook on life. }\end{array}$ & $\begin{array}{l}\text { Hysterical } \\
\text { fugue? }\end{array}$ & 2 & 1 & 0 & $29 \cdot 5$ \\
\hline N6 & $\begin{array}{l}\text { Worries about wife being pregnant and not having married } \\
\text { quarters. A quiet, inadequate, shy person who suddenly } \\
\text { attacked his mother-in-law. }\end{array}$ & $\begin{array}{l}\text { Reactive } \\
\text { depression }\end{array}$ & 1 & 1 & 1 & $15 \cdot 3$ \\
\hline $\mathbf{N} 7$ & $\begin{array}{l}\text { Complains of headaches caused by exertion. Has to lie down } \\
\text { where it is nice and quiet. Puts on a great and continual } \\
\text { show of suffering. }\end{array}$ & Hysteria & 3 & 1 & 0 & $57 \cdot 8$ \\
\hline N8 & $\begin{array}{l}\text { Neck twists towards one side from time to time. No pain. } \\
\text { Pleasant cheerful manner, seems quite indifferent to illness. }\end{array}$ & $\begin{array}{l}\text { Torsion } \\
\text { spasm }\end{array}$ & 2 & 0 & 0 & $36 \cdot 0$ \\
\hline N9 & $\begin{array}{l}\text { Complains of pains in chest. Fears tuberculosis. Palpitations, } \\
\text { funny feelings inside. Worries about masturbation and } \\
\text { homosexual practices. }\end{array}$ & $\begin{array}{l}\text { Anxiety } \\
\text { state }\end{array}$ & 1 & 1 & 0 & $37 \cdot 0$ \\
\hline N10 & $\begin{array}{l}\text { Worries about lack of manliness, bad nerves. Cannot sleep. } \\
\text { Dizzy spells, palpitations, headaches, tremor on excitement. } \\
\text { Quiet and retarded. }\end{array}$ & $\begin{array}{l}\text { Reactive } \\
\text { depression }\end{array}$ & 0 & 1 & 2 & $28 \cdot 0$ \\
\hline N11 & $\begin{array}{l}\text { Browned off. Has had vague ideas of suicide. Moody, always } \\
\text { in trouble and always rowing with people. Dreamt last night } \\
\text { he poisoned sergeant's mother. }\end{array}$ & Psychopath & 0 & 0 & 1 & $56 \cdot 5$ \\
\hline $\mathrm{N} 12$ & $\begin{array}{l}\text { Fed up with the Army, always in trouble. Always late for } \\
\text { parades. "They tell me off and it makes me worse." }\end{array}$ & $\begin{array}{l}\text { Anxiety } \\
\text { state }\end{array}$ & 1 & 1 & 1 & $50 \cdot 7$ \\
\hline N13 & $\begin{array}{l}\text { Complains of memory slips, feelings of unreality. When his } \\
\text { mind gets clearer he begins to tremble. A tense, rigid } \\
\text { personality. }\end{array}$ & $\begin{array}{l}\text { Anxiety, } \\
\text { derealization }\end{array}$ & 0 & 1 & 2 & $34 \cdot 9$ \\
\hline N14 & $\begin{array}{l}\text { Must continually wear his hat because he cannot bear people to } \\
\text { see that he is going bald. Has to eat separately in his hat. } \\
\text { Thinks about nothing else. }\end{array}$ & $\begin{array}{l}\text { Obsessional } \\
\text { state }\end{array}$ & 0 & 0 & 0 & $31 \cdot 5$ \\
\hline N15 & $\begin{array}{l}\text { Complains of tremor of abdominal muscles, arms, and legs. } \\
\text { The Army is to blame. Also has palpitations and dizzy } \\
\text { spells. "They ought to send me home." }\end{array}$ & Hysteria & 3 & 1 & 0 & $75 \cdot 6$ \\
\hline N16 & $\begin{array}{l}\text { Complains of domestic worries. Cannot be happy anywhere. } \\
\text { Intends to desert. Does not seem very anxious or depressed } \\
\text { on examination. }\end{array}$ & $\begin{array}{l}\text { Psychopath } \\
\text { with some } \\
\text { anxiety }\end{array}$ & 0 & 1 & 0 & $20 \cdot 2$ \\
\hline N17 & $\begin{array}{l}\text { Has had headaches and depression with suicidal thoughts since } \\
\text { groin strain prevented his beloved sprinting. Narcissistic, } \\
\text { body conscious, rigid person. }\end{array}$ & $\begin{array}{l}\text { Reactive } \\
\text { depression }\end{array}$ & 1 & 0 & 2 & $33 \cdot 4$ \\
\hline N18 & $\begin{array}{l}\text { Complains of lack of confidence, shyness, fears of being } \\
\text { homosexual. Worse for past two years. A good basic } \\
\text { personality, capable and likeable. }\end{array}$ & Depression & 0 & 1 & 2 & $14 \cdot 5$ \\
\hline N19 & $\begin{array}{l}\text { Depression, easily flustered and upset since bad shelling in } \\
\text { ltaly. Tires easily, has dizzy spells and palpitations. }\end{array}$ & $\begin{array}{l}\text { Chronic } \\
\text { anxiety state }\end{array}$ & 1 & 2 & 1 & $30 \cdot 0$ \\
\hline $\mathrm{N} 20$ & $\begin{array}{l}\text { Dizzy spells, tremor from waist downwards, " jitters" since a } \\
\text { serious artillery accident. Much aggression towards } \\
\text { authority. }\end{array}$ & $\begin{array}{l}\text { Traumatic } \\
\text { neurosis }\end{array}$ & 1 & 1 & 0 & $12 \cdot 3$ \\
\hline N21 & $\begin{array}{l}\text { Dizzy spells, blackouts since joining Army. Much weeping on } \\
\text { interview. Blackouts occur when he thinks about home. }\end{array}$ & $\begin{array}{l}\text { Reactive } \\
\text { depression }\end{array}$ & 2 & 1 & 2 & $37 \cdot 9$ \\
\hline $\mathrm{N} 22$ & $\begin{array}{l}\text { Complains of about } 30 \text { obsessional habits "which I write down } \\
\text { for the Command psychiatrist." Mood labile, irritable. } \\
\text { Little tension. }\end{array}$ & $\begin{array}{l}\text { Obsessive } \\
\text { personality }\end{array}$ & 0 & 0 & 0 & $24 \cdot 3$ \\
\hline $\mathrm{N} 23$ & $\begin{array}{l}\text { Complains of having no emotions. "Every time I kiss my wife } \\
\text { I feel like belting her." Very perfectionistic. }\end{array}$ & $\begin{array}{l}\text { Depression, } \\
\text { derealization }\end{array}$ & 0 & 0 & 1 & $17 \cdot 2$ \\
\hline $\mathrm{N} 24$ & $\begin{array}{l}\text { Suicidal attempt with morphine after being told that his } \\
\text { recently adopted homosexual practices could not be cured. }\end{array}$ & $\begin{array}{l}\text { Reactive } \\
\text { depression }\end{array}$ & 0 & 1 & 2 & $28 \cdot 7$ \\
\hline $\mathrm{N} 25$ & $\begin{array}{l}\text { Complains of lack of concentration, restless, always losing } \\
\text { temper with authorities and with wife, sense of internal } \\
\text { excitement. Wants to fight his way out. }\end{array}$ & $\begin{array}{l}\text { Tension } \\
\text { state }\end{array}$ & 1 & 1 & $\theta$ & $87 \cdot 1$ \\
\hline N26 & $\begin{array}{l}\text { Preoccupied with thought of having V.D. Dizzy spells, night } \\
\text { terrors, palpitations, headaches. Has always been babied } \\
\text { excessively. }\end{array}$ & $\begin{array}{l}\text { Anxiety } \\
\text { state }\end{array}$ & 1 & 2 & 1 & $41 \cdot 6$ \\
\hline N27 & $\begin{array}{l}\text { Headaches, retardation, poor sleep since concussion } 5 \text { months } \\
\text { previously. Always has been shy and suffered from bad } \\
\text { nerves. }\end{array}$ & Depression & 0 & 1 & 2 & $16 \cdot 7$ \\
\hline N28 & $\begin{array}{l}\text { Always tired, depressed, cannot eat or sleep since girl jilted } \\
\text { him } 18 \text { months previously. Suicidal attempt. }\end{array}$ & Depression & 0 & 1 & 2 & $22 \cdot 9$ \\
\hline N29 & $\begin{array}{l}\text { Complains of suicidal tendencies. Weeps a great deal, talks } \\
\text { incessantly of domestic worries including religious wife who } \\
\text { neglects him. }\end{array}$ & $\begin{array}{l}\text { Inadequate, } \\
\text { hysterical }\end{array}$ & 2 & 1 & 1 & $47 \cdot 9$ \\
\hline N30 & $\begin{array}{l}\text { Complains of bad nerves all his life. Gets pains in head when } \\
\text { people shout at him. Cannot stand filthy language. Pains } \\
\text { in chest. }\end{array}$ & $\begin{array}{l}\text { Anxiety- } \\
\text { hysteria }\end{array}$ & 2 & 1 & 0 & $25 \cdot 4$ \\
\hline N31 & $\begin{array}{l}\text { Dizziness, blackouts, and headaches caused by noise. Many } \\
\text { tears during interview. }\end{array}$ & $\begin{array}{l}\text { Hysterical, } \\
\text { inadequate }\end{array}$ & 3 & 1 & 0 & $61 \cdot 0$ \\
\hline N32 & $\begin{array}{l}\text { No appetite, head has felt heavy for } 6 \text { months. Many anxiety } \\
\text { symptoms. He is falsely mocked as a homosexual by his } \\
\text { fellows. }\end{array}$ & $\begin{array}{l}\text { Inadequate } \\
\text { Anxiety } \\
\text { state }\end{array}$ & 0 & 1 & 1 & $26 \cdot 7$ \\
\hline
\end{tabular}




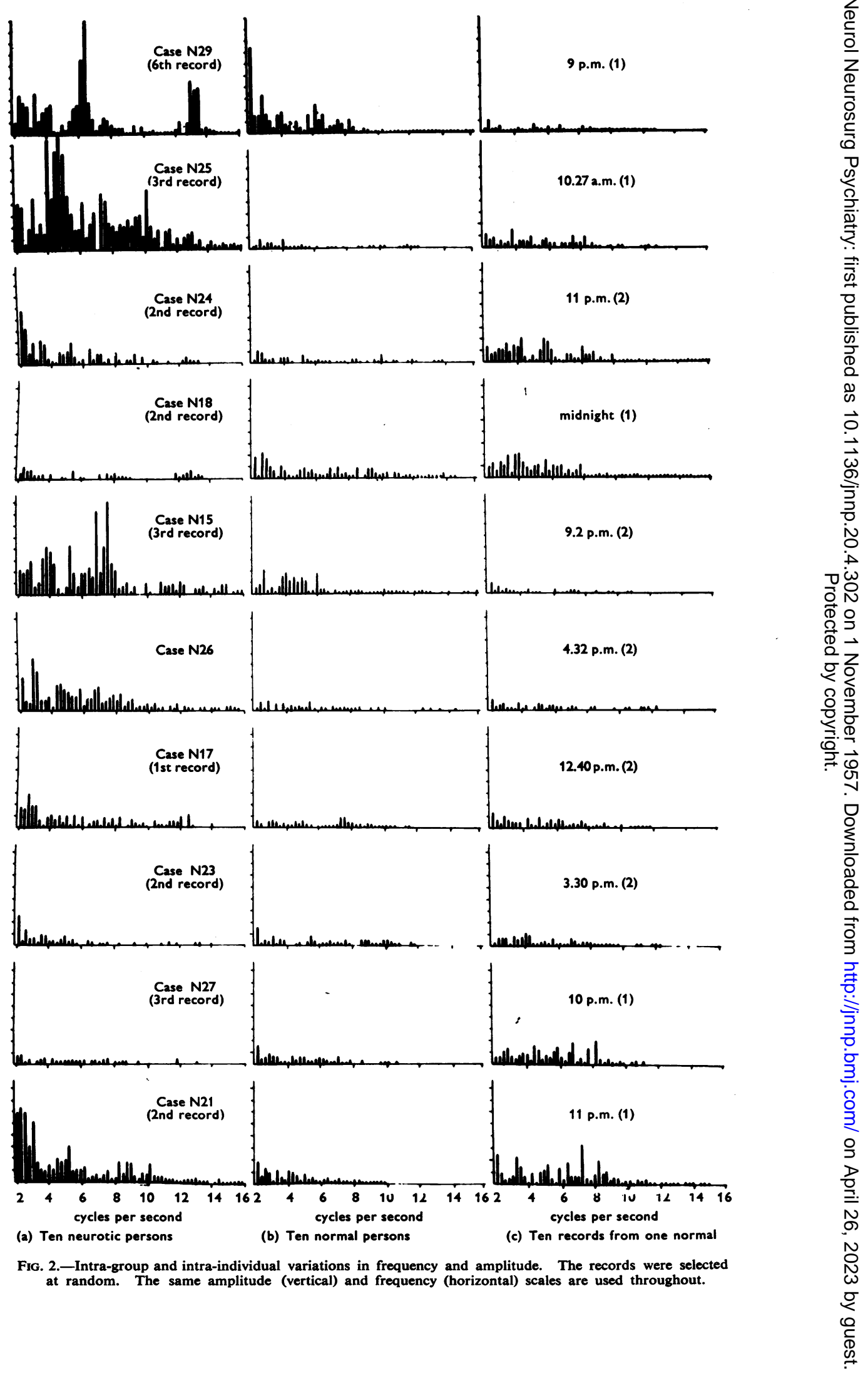


illness, and from anxiety symptoms and signs at interview. Although at first sight easier to rate than hysteria as defined above, it was in practice less satisfactory, as the various alleged manifestations of anxiety are relatively independent of each other in their occurrence.

None of the patients in the neurotic group was severely depressed. Each neurotic patient was rated according to whether he was not depressed, or mildly depressed, or moderately depressed, as judged mainly from his own statements. In all the ratings zero means that the characteristic was absent and the other figures are in increasing order of severity.

\section{Results}

The results given below apply to the tremor of the right index finger, although they seem to apply qualitatively to other fingers and indeed to other parts of the body. The main clinical features, clinical diagnosis, ratings, and the mean angular finger velocity of each neurotic subject are recorded in Table I. The mean finger velocity for the neurotic group was 36.6 radians per sec. $\times 10^{-3}$ (S.D. $18 \cdot 4$ radians/sec. $\left.\times 10^{-3}\right)$. The mean finger velocity of the normal group was 18.3 radians/sec. $\times 10^{-3}$ (S.D. 4.9 radians/sec. $\times 10^{-3}$ ). About half of the neurotic group have values higher than the highest normal value. The clinical findings in the normal group are not given here as apart from two ratings of one in "hysteria" and one in " anxiety" they were entirely negative.

A random sample of neurotic and normal frequency spectra is shown in Fig. 2, together with 10 spectra from one normal individual taken at different times of the day. It is seen that both amplitude and frequency composition show the same sort of variations between individuals as in the same individual at different times, although the extent of the latter source of variance is not, of course, so large. Variations in harmonic composition in the same individual occur over periods of seconds. Samples of records of 10 seconds duration do not show nearly as much variation as the four-second samples shown.

Instead of analysing a sample of record of longer duration, corresponding lines of different spectra from the same individual may be averaged (Fig. 3) to form a composite spectrum for the individual. The same procedure may be followed for a group of individuals. The composite spectrum for groups of individuals is similar to the composite spectrum of one individual, but not identical, as there are some differences of harmonic composition between individuals.

The main objection to the taking of simple means in order to arrive at average or composite spectra is that, if the distribution of tremor amplitudes among individuals were not normal but skewed, the composite spectrum would over-emphasize higher or lower values. Tremor amplitudes do, in fact, have a markedly skewed distribution, such that the logarithms of the amplitudes have a much more nearly normal distribution than do the amplitudes themselves. It is therefore, strictly speaking, far less exceptionable to obtain a composite spectrum for a group only when all members of the group have comparable amplitudes. To square amplitudes and obtain root mean square values for a group of individuals, as some physicists would do, would mean that the composite root mean square spectrum

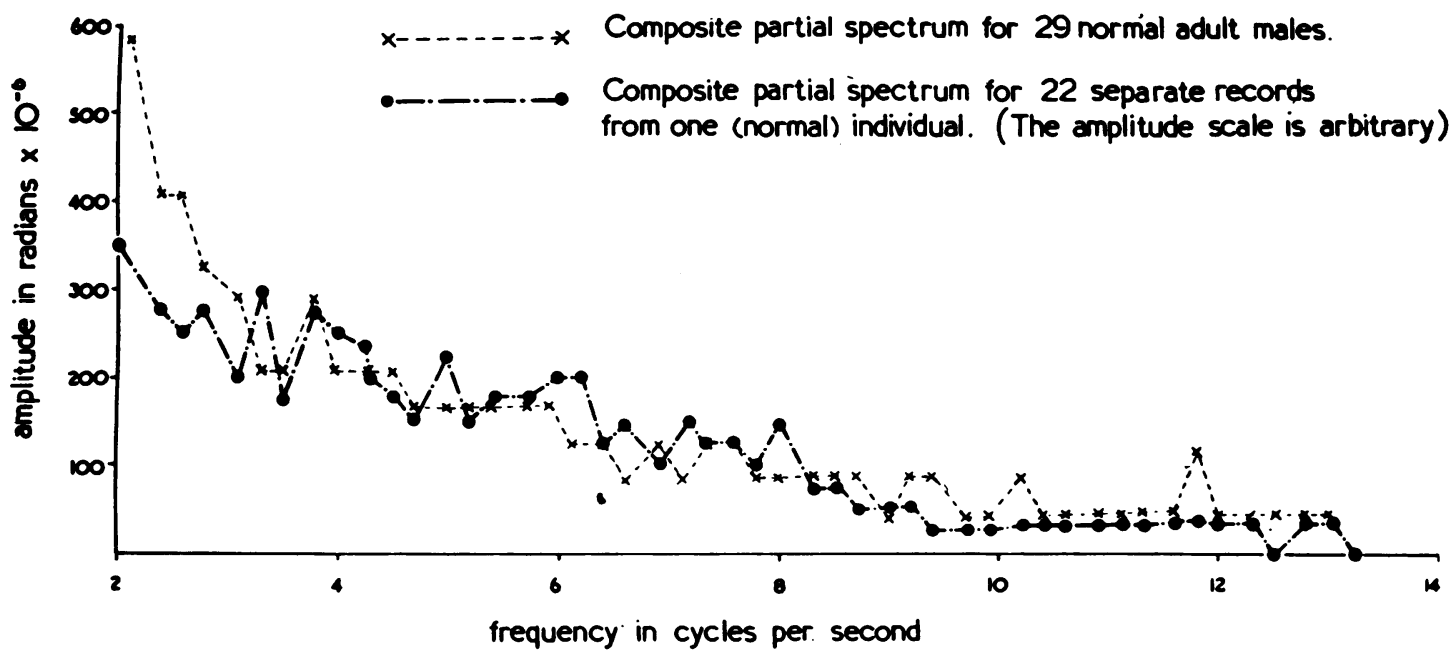

Fig. 3.-The composite spectrim of one normal individual. 


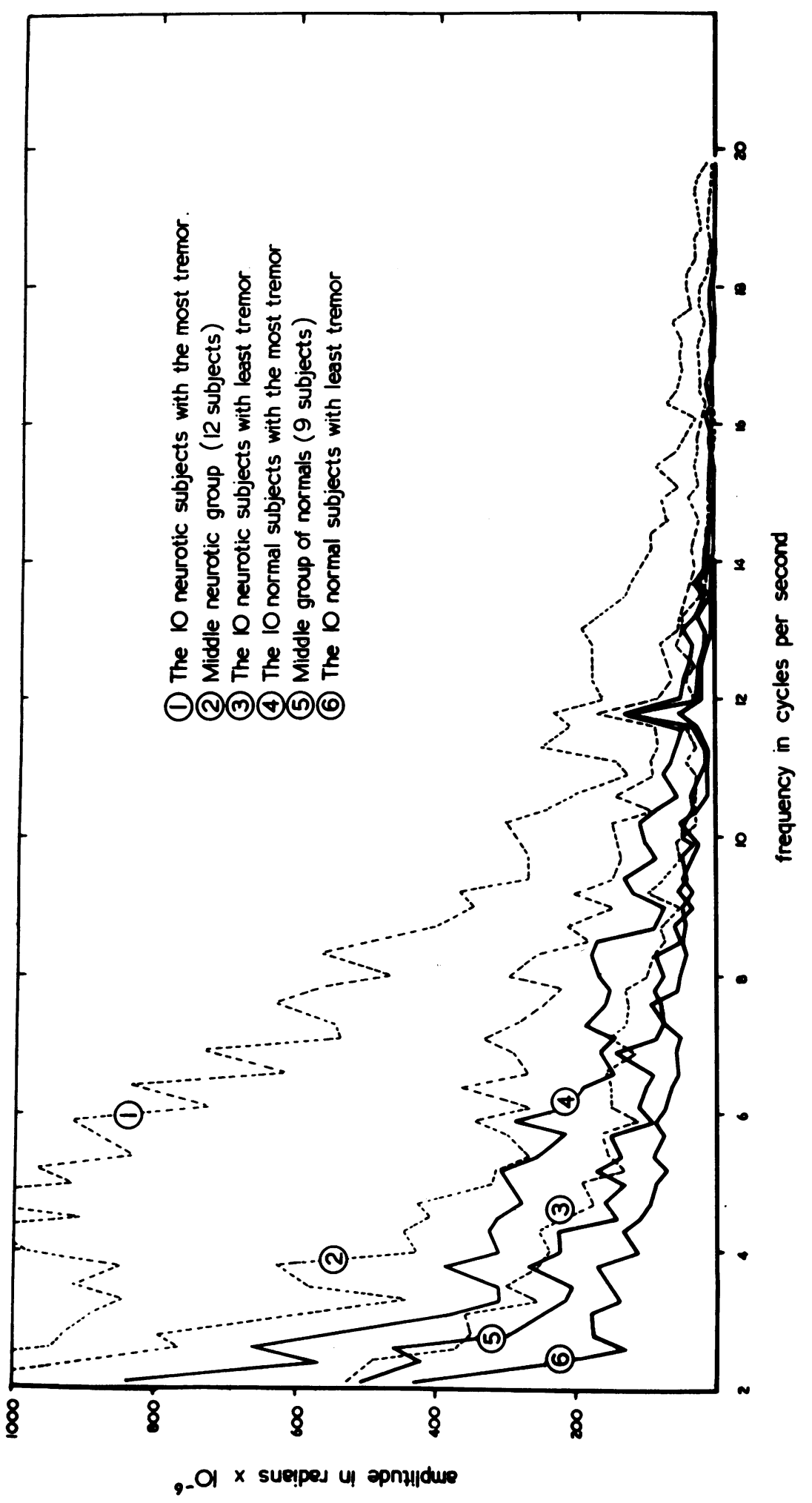




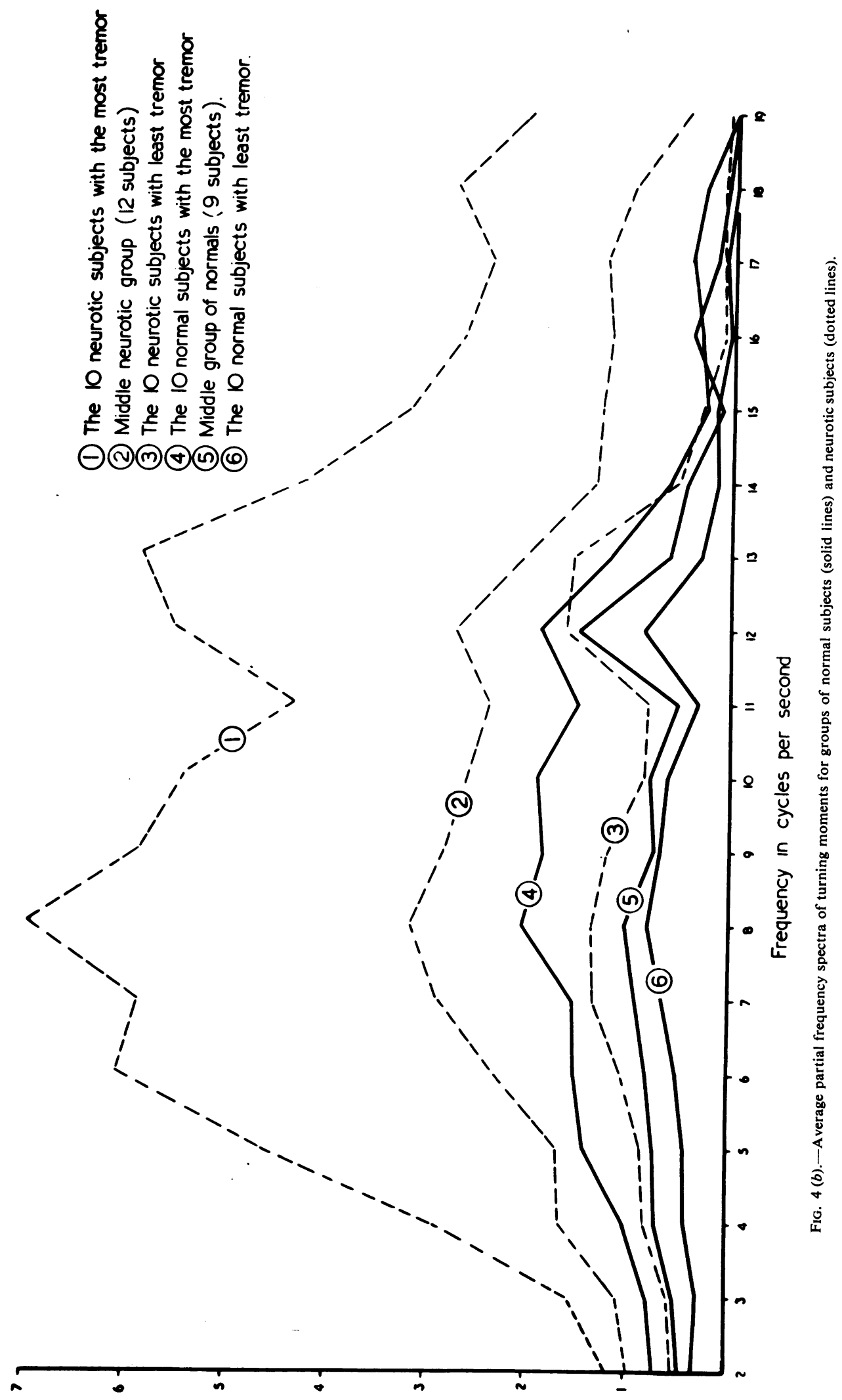

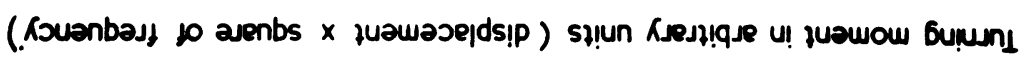


for a group would, in fact, merely be the spectrum of the one or two individuals with the largest amplitude.

If the tremor spectra of individuals with comparable amplitude are meaned, displacement spectra for neurotic and normal sub-groups are obtained as in Fig. $4(a)$. These displacement spectra represent the frequencies of tremor as seen clinically. The spectrum for the high-amplitude neurotic group appears qualitatively different from those of the other groups in that there is a hump around 5 or $6 \mathrm{c}$./sec. (as in Charcot's teaching). The other spectra appear to fall off in amplitude progressively with frequency more or less in accordance with the relationship

amplitude $\times$ square of frequency $=a$ constant (cf. Halliday and Redfearn, 1956).

The sharp peak in all the spectra at just under $12 \mathrm{c}$./sec. is an artefact caused by using squared paper on the frequency analyser.

Displacement spectra are of no great interest apart from representing the clinician's sensory data. To represent the forces playing upon the trembling part, acceleration spectra (Fig. $4(b))$ are obtained from the displacement spectra by multiplying the latter by the square of the frequency. (Again, the values for $12 \mathrm{c}$./sec. should be ignored.) It is now seen that all the sub-groups show forces acting with peak amplitudes at around 8 or $9 \mathrm{c}$. $/ \mathrm{sec}$. This suggests that the mechanism underlying the tremor of all the sub-groups is a common mechanism causing muscular forces to fluctuate with a rhythm of 8 or $9 \mathrm{c} . / \mathrm{sec}$.

\section{Tremor Frequency and Diagnosis}

From the neurotic patients were selected those fitting most readily into the commonly accepted diagnostic categories, namely, hysteria, anxiety state, reactive depression, and so on. From each case a tremor record was selected at random and these records are presented together in Fig. 5. It is obvious that there are no well-marked differences in frequency content from one diagnostic group to another, although there is a suggestion, borne out statistically, of a greater amplitude in the case of hysterical patients and a smaller amplitude in the case of the depressed patients than in their neurotic fellows. The composite displacement and acceleration spectra for the patients with high hysteria and anxiety ratings, as compared with the normal group, are respectively shown in Figs. $6(a)$ and $(b)$. As with Fig. $4(a)$, comparison of the displacement spectra shows a tendency for the hysterical group to show a bulge at around 5 or $6 \mathrm{c}$./ $/ \mathrm{sec}$. and for the anxiety group to show a bulge at around $8 \mathrm{c}$./ $/ \mathrm{sec}$., as does the normal group. Again this observation accords well with those of Charcot and his pupils. However, the acceleration spectra, which can be taken approximately to represent the muscular forces involved, show up the large degree of similarity of frequency distribution among the different diagnostic categories.

\section{Stretch Reflexes and Tremor Amplitude}

These findings will be described more fully in a later communication. It is sufficient here to state that in the normal group there was no correlation between the size of the reflex response to sudden stretch on the one hand and tremor amplitude on the other. In the neurotic group, however, there was a significant positive correlation between the two variates. The observations on the normal group agree with those of Halliday and Redfearn (1956).

\section{Discussion}

The visual inspection of a trembling limb or of a tremor record gives only an extremely approximate idea of the frequency components of the tremor, except in the case of a more or less pure rhythm such as occurs in Parkinsonism. The main reason for this unreliability is that one tends to perceive only the high frequency components of a tremor andत to ignore the low frequency components (Redfearn, 1956). Although for some experimental purposes it is possible to select a subject who often shows a very pure and well marked rhythm, the only valid method of describing the tremor of most individuals over a period of minutes or longer, or of describing the tremor of a group of individuals, would seem to be in terms of a frequency spectrum.

As it is muscular forces which are responsible for tremor, it is the frequency distribution of these forces (or the accelerations which result from these forces and which are directly proportional to them) which is of greatest interest. Whether we divide our neurotic population according to amplitude of tremor or according to diagnosis, it is clear that the most striking finding, indeed the only reliable finding, is of a similarity of the shape of the spectra not only with each other but with the spectrum of the group of normal individuals. Both the normal and the neurotic spectra show, first, tremor at all frequencies which by analogy can be termed noise, i.e., random activity at all frequencies. Secondly, there is a distinct peak around $8 \mathrm{c}$./sec. in all groups.

The neurotic group as a whole shows a sub-peak at $13 \mathrm{c} . / \mathrm{sec}$., but this finding cannot be considered reliable, as the displacement spectra, from which these acceleration spectra were obtained (by multiplying by frequency squared), were diminishing rapidly at this frequency and were not much above the noise level of the apparatus. A much more 

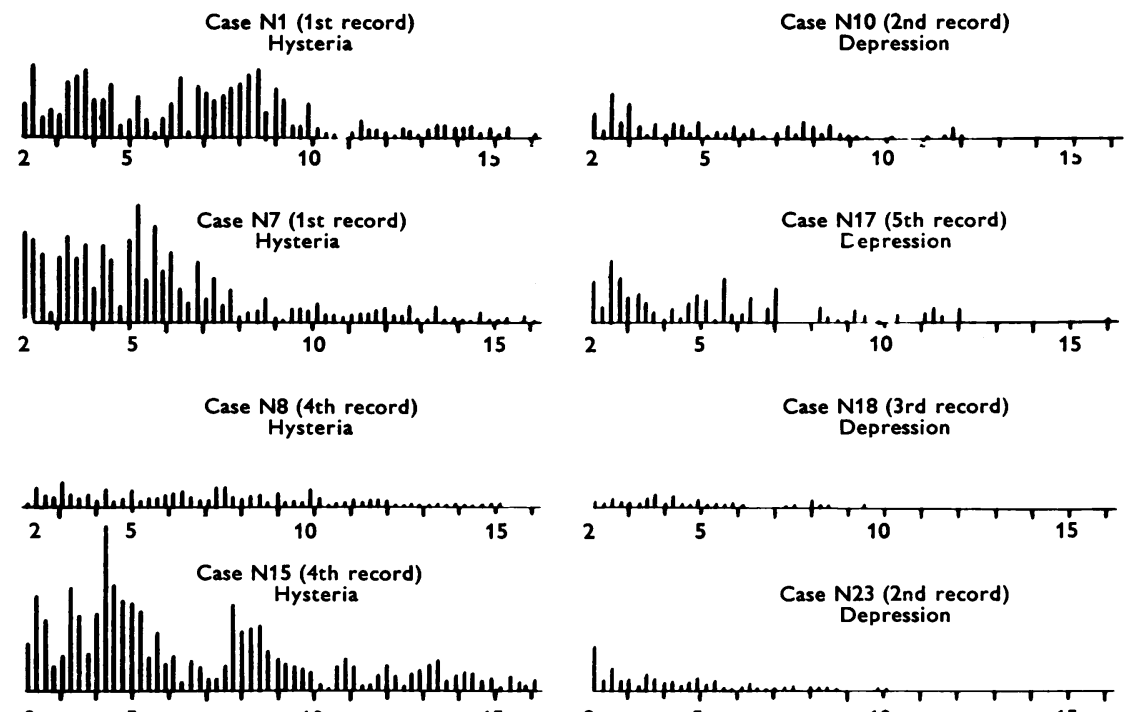

2
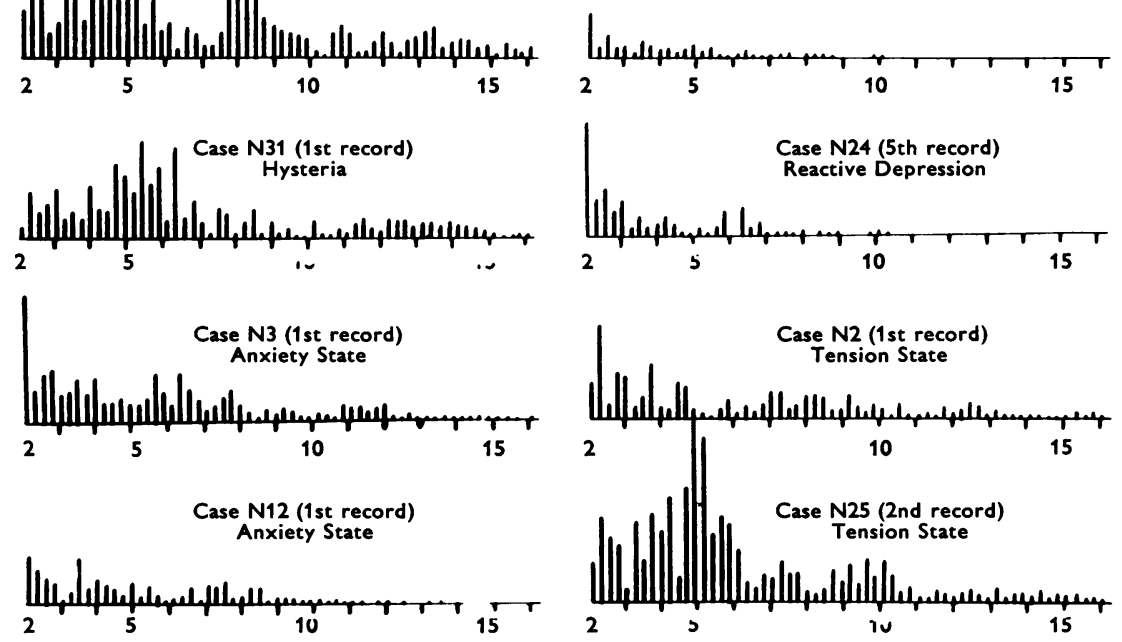

Case N12 (1st record)

$$
\text { Anxiety State }
$$

Case N19 (2nd record)

Anxiety State
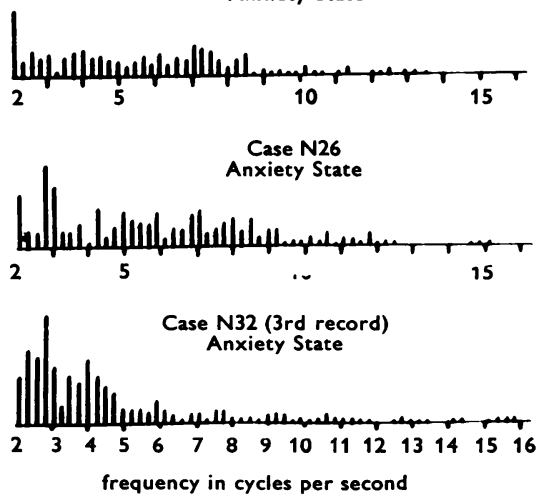
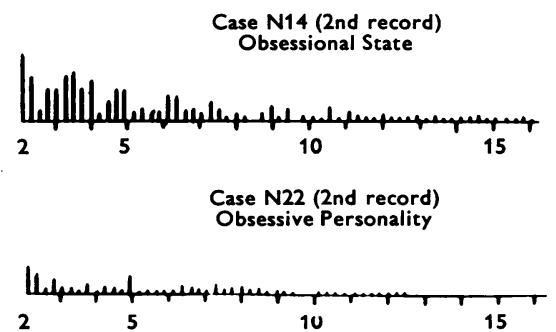

Case N13 (4th record)

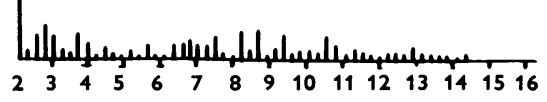

frequency in cycles per second

FIG. 5.-Tremor and diagnosis: displacement frequency spectra of randomly selected records from typical cases of various diagnostic categories. The same amplitude scale is used throughout. 


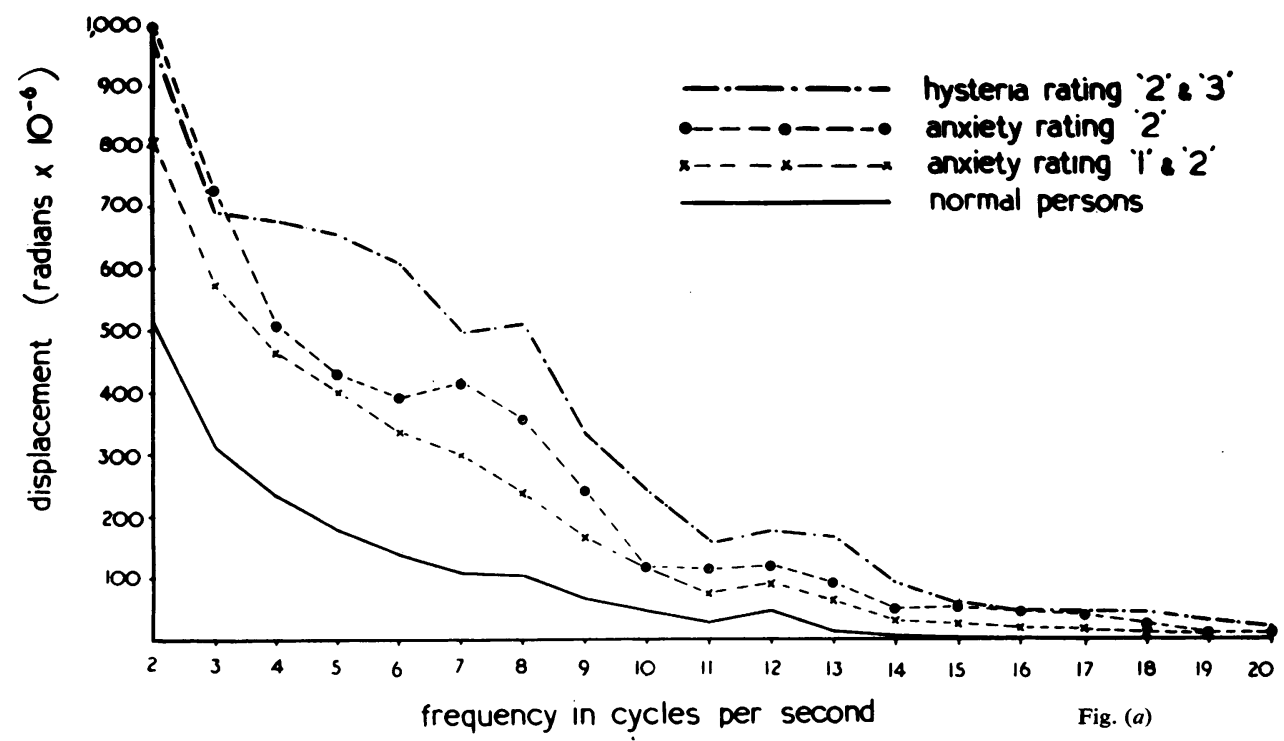

FIG. 6 (a).-Average displacement frequency spectra, and (b) average turning-moment frequency spectra of hysterical patients, patients

$$
\text { 츨 }
$$
showing anxiety, and normal persons compared.

Fig. (a)

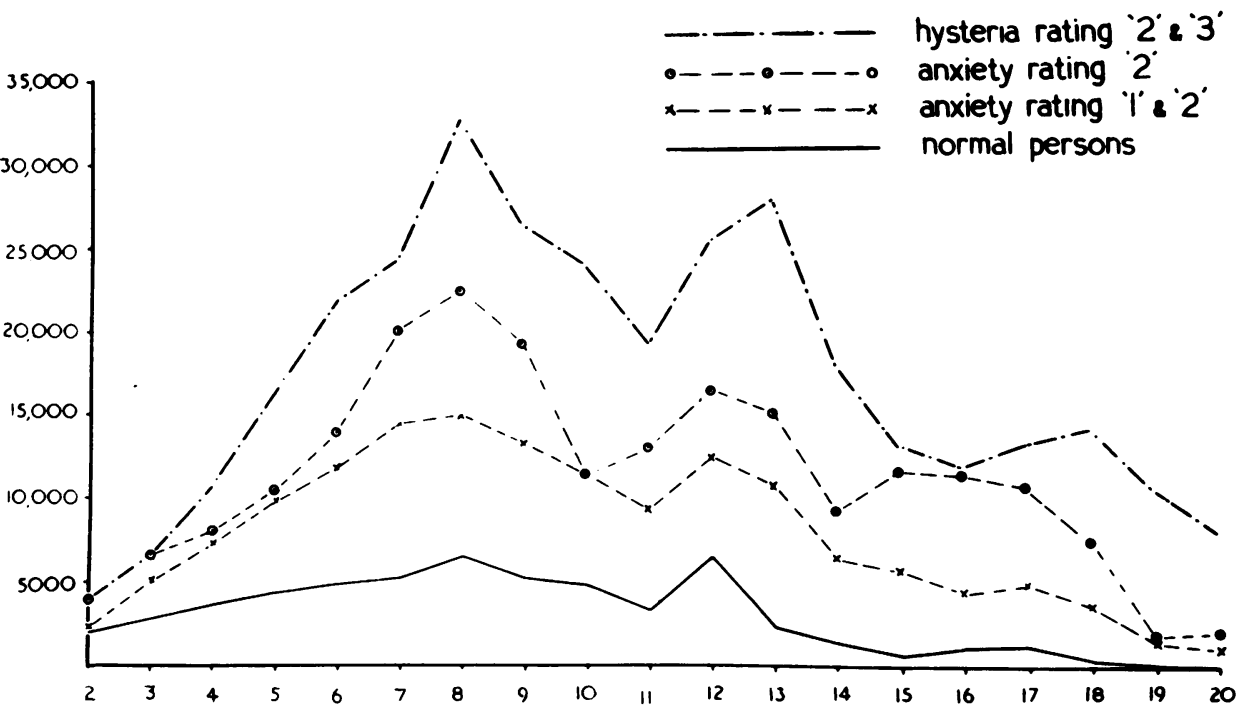

frequency in cycles per second

Fig. (b)

reliable finding is a sub-peak or bulge at 5-6 c./sec. in the acceleration spectra, and particularly noticeable in the displacement spectra, of those neurotic subjects with the tremor of greatest amplitude. In the groups studied here, and evidently in Charcot's experience, the subjects with the tremor of greatest amplitude were often hysterical, but no definite rule is possible. 
Generalizations are only possible about dominant frequencies if the tremor is recorded over longer periods than the four or five seconds of record from which were obtained the individual spectra shown in this paper. During periods of a few seconds there may be waves or runs of waves at any frequency between about 5 and 12 , or even more, so that the spectrum shows a marked hump or perhaps two or three humps at the corresponding frequency or frequencies. In order to obtain a smooth and reproducible spectrum from one individual it is preferable to record tremor over a minute or two, although this depends somewhat on the method of frequency analysis in use.

From the similarity of the general shape of the force spectra of the normal and neurotic groups, and also from the similarity in general character of the tremor trace (apart from amplitude), it can be argued that whatever the factors are which determine tremor frequency, normal and neurotic tremors may well possess these factors in common, to a large extent. Even the apparent differences, for example, the increased activity at about $5 \mathrm{c}$./ $\mathrm{sec}$. in the grossly tremulous neurotics, probably only represent exaggerations of normal processes, because slow waves or runs of slow waves do occur in normal records.

It is shown elsewhere (see Lippold, Redfearn, and Vučo, 1957a, for a preliminary communication) that a peak of activity at 8-10 c./sec. occurs in the tremors of emotion (waiting for an important interview), of shivering from cold, of muscular fatigue, and of thyrotoxicosis. It would appear that, as a first approximation at least, neurotic tremors may in many or most cases be placed in this category of tremors. Of course, it is only to be expected that with refinements of technique and larger numbers of subjects, valid distinctions between subgroups may be possible.

Evidence is presented elsewhere (Halliday and Redfearn, 1956, 1957; Lippold et al., 1957a and b) which can be interpreted as supporting the hypothesis that the mechanism underlying the $8-10 \mathrm{c}$. $/ \mathrm{sec}$. peak is "hunting" in the stretch reflex servo loop. However this may be, the mechanism underlying the random or noisy element of tremor, possibly the more important element, and the mechanisms underlying the variations in amplitude of tremor, remain unclear. Any tendency towards synchronous firing of motoneurones would increase the random element of tremor, and there are undoubtedly several ways in which this tendency might be brought about, including motoneurone damage and increased Renshaw inhibition.
Summary

Finger tremor was recorded by a photo-electric method in 29 young adult normal male subjects and 32 psychoneurotic subjects of similar age, sex, and background. The tremor records were subjected to automatic frequency analysis. Each control and neurotic subject had a psychiatric interview and was rated for hysterical features, anxiety, and depression.

The neurotic group was subdivided according to (a) diagnosis and (b) magnitude of tremor. However, the group was sub-divided, the subgroups all showed fundamentally the same shape of frequency spectrum as each other and as the normal group. The peak of tremor activity in all groups occurred at about $8 \mathrm{c}$. $/ \mathrm{sec}$., rising from a plateau of random or irregular activity. The neurotic subjects with the most tremor showed a sub-peak at 5-6 c./sec. and these neurotic subjects were often the ones with high ratings in hysteria. Compared with the main peak this sub-peak is not very marked in terms of the forces involved. The general amplitude of tremor was, of course, much higher in the neurotic group as a whole than in the normal group. The fundamental similarity in frequency spectra, apart from the relative size of the 5-6 cycle component, suggest that the mechanisms which determine tremor frequency may be largely common to both normal and neurotic groups, although the mechanisms determining amplitude are clearly more active among the neurotic subjects.

\section{REFERENCES}

Barber, N. F., Ursell, F., Darbyshire, J., and Tucker, M. J. (1946). Nature (Lond.), 158, 329.

Bleuler, E. (1924). Textbook of Psychiatry, p. 543. Trans. by Brill, A. A. Macmillan, New York.

Charcot, J. M. (1888). Leçons du Mardi à la Salpêtrière (1887-1888). Leçon du 22 Mai, 1888.

(1889). Clinical Lectures on Diseases of the Nervous System 1st ed., vol. 3, pp. 183-197. Trans. by Savill, T. The New Sydenham Society, London.

Cooper, J. D., Halliday, A. M., and Redfearn, J. W. T. (1957). Electroenceph. clin. Neurophysiol., 9, 546.

Dutil, M. A. (1891). Contribution à l'étude clinique des tremblements hystériques. M.D. Thesis. Paris.

Halliday, A. M., and Redfearn, J. W. T. (1956). J. Physiol. (Lond.), 134,600 .

- 1 (1957). “Finger Tremor in Tabetic Patients, and its Bearing on the Mechanism Producing Tremor in Healthy Subjects." Fourth International Congress of Electroencephalography and Clinical Neurophysiology, pp. 153-154. (Excerpta med. (Amst.), p. 153.)

Lippold, O. C. J., Redfearn, J. W. T., and Vuco, J. (1957a). “The Relation between the Stretch Reflex and the Electrical and Mechanical Rhythmicity in Human Voluntary Muscle." Proceedings of the Physiological Society, 19-20 July, 1957. J. Physiol. (Lond.) In the press.

Marey, E. J. (1868). Du mouvement dans les fonctions de la vie. Germer Baillière, Paris.

Mott, F. W. (1919). War Neuroses and Shell Shock, 1st ed., p. 159. Hodder and Stoughton, London.

Redfearn, J. W. T. (1956). Finger Tremor. M.D. Thesis. Cambridge. 1957). Finger Tremor in Normal and Neurotic Soldiers. A.O.R.G. Report 3/57. Dept. of the Scientific Adviser to the Army Council, War Office.

Schäfer, E. A. (1886). J. Physiol. (Lond.), 7, 111. 